\title{
Vertebral Osteomyelitis Caused by Helicobacter cinaedi Identified Using Broad-range Polymerase Chain Reaction with Sequencing of the Biopsied Specimen
}

\author{
Ryota Hase $^{1}$, Takuya Hirooka ${ }^{2}$, Takashi Itabashi ${ }^{2}$, Yasunobu Endo ${ }^{3}$ and Yoshihito Otsuka ${ }^{4}$
}

\begin{abstract}
:
A 65-year-old man presented with gradually exacerbating low back pain. Magnetic resonance imaging revealed vertebral osteomyelitis in the Th11-L2 vertebral bodies and discs. The patient showed negative findings on conventional cultures. Direct broad-range polymerase chain reaction (PCR) with sequencing of the biopsied specimen had the highest similarity to the 16S rRNA gene of Helicobacter cinaedi. This case suggests that direct broad-range PCR with sequencing should be considered when conventional cultures cannot identify the causative organism of vertebral osteomyelitis, and that this method may be particularly useful when the pathogen is a fastidious organism, such as $H$. cinaedi.
\end{abstract}

Key words: vertebral osteomyelitis, Helicobacter cinaedi, broad-range PCR with sequencing

(Intern Med 57: 1475-1477, 2018)

(DOI: 10.2169/internalmedicine.0012-17)

\section{Introduction}

Both blood and biopsy specimen cultures are useful diagnostic tests for confirming the causative pathogen of vertebral osteomyelitis. However, the positivity rates of both tests have been reported to be limited to $58 \%$ and $77 \%$, respectively (1). Recently, broad-range $16 \mathrm{~S}$ rRNA gene polymerase chain reaction combined with sequencing [broad-range polymerase chain reaction (PCR) with sequencing] has been used to identify the causative pathogen in cases where conventional cultures are negative (2). Using this new technique, the causative pathogen is accurately identified by gene amplification and sequencing of a broad-range gene target for bacteria (3).

We herein report the case of a 65 -year-old man with vertebral osteomyelitis caused by Helicobacter cinaedi confirmed using broad-range PCR with sequencing that had not been identified by either blood or biopsy specimen cultures.

\section{Case Report}

The patient was a 65-year-old man without any significant medical history. He presented with gradually exacerbating low back pain for the past year. He denied a fever or any associated neurological symptoms. He did not have an immunocompromised background.

On admission, his vital signs were as follows: blood pressure, $141 / 73 \mathrm{mmHg}$; heart rate, 77 beats/min; body temperature, $36.3^{\circ} \mathrm{C}$; respiratory rate, 20 breaths $/ \mathrm{min}$; and oxygen saturation on room air, 95\%. A physical examination revealed knock pain at the L1 level but no abnormal neurological findings. Laboratory tests showed an elevated Creactive protein (CRP) level $(3.36 \mathrm{mg} / \mathrm{dL}$; normal, $<0.3 \mathrm{mg} /$ $\mathrm{dL})$ and an elevated erythrocyte sedimentation rate $(41 \mathrm{~mm} /$ h; normal, $<14 \mathrm{~mm} / \mathrm{h}$ ). His white blood cell count, hemoglobin level, platelet count, serum electrolyte level, plasma glucose level, liver function test results, and creatine phosphokinase level were all normal. Magnetic resonance imaging revealed findings of vertebral osteomyelitis in the Th11-L2

\footnotetext{
${ }^{1}$ Department of Infectious Diseases, Japanese Red Cross Narita Hospital, Japan, ${ }^{2}$ Department of Orthopedics, Japanese Red Cross Narita Hospital, Japan, ${ }^{3}$ Department of Laboratory Medicine, Japanese Red Cross Narita Hospital, Japan and ${ }^{4}$ Department of Laboratory Medicine, Kameda Medical Center, Japan

Received: August 1, 2017; Accepted: October 16, 2017; Advance Publication by J-STAGE: January 11, 2018

Correspondence to Dr. Ryota Hase, ryota510@ hotmail.com
} 


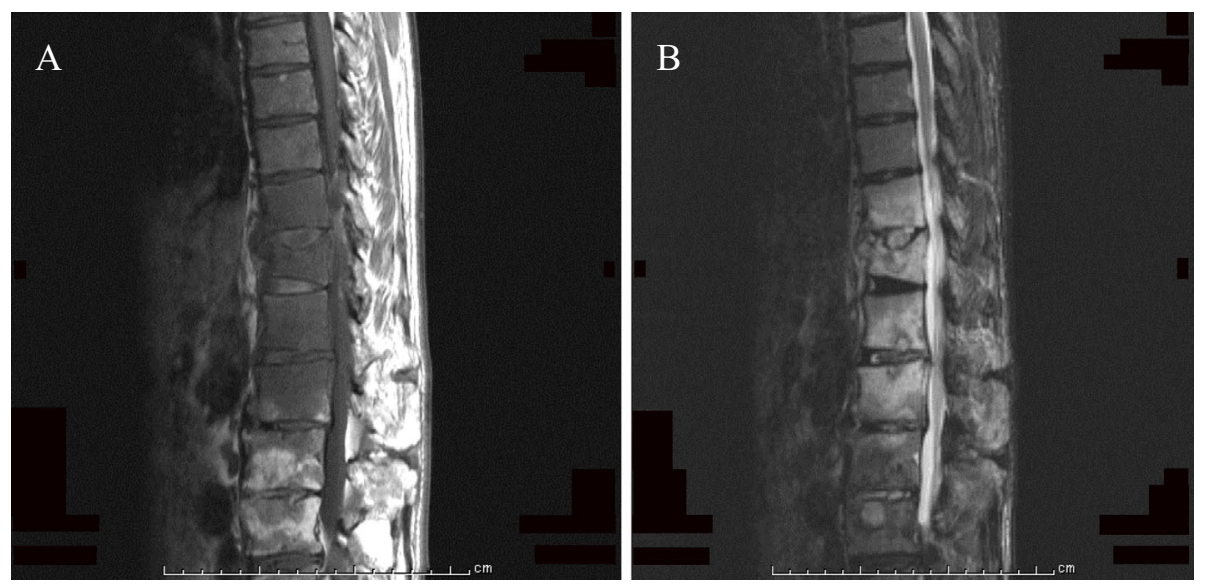

Figure. Magnetic resonance imaging. The image in A was taken with TI-weighted imaging, showing a low signal in the Th11-L2 vertebral bodies and disks. The image in B was taken with T2-weighted short-tau inversion recovery imaging, showing a high signal in the Th11-L2 vertebral bodies and disks.

Table. A Summary of Five Cases of Vertebral Osteomyelitis Caused by Helicobacter cinaedi Reported in the English Literature along with the Present Case.

\begin{tabular}{|c|c|c|c|c|c|c|c|c|c|}
\hline Case & $\begin{array}{l}\text { Age, } \\
\text { years/ } \\
\text { sex }\end{array}$ & $\begin{array}{l}\text { Underlying } \\
\text { conditions }\end{array}$ & $\begin{array}{c}\text { Site of } \\
\text { infection }\end{array}$ & $\begin{array}{l}\text { Blood } \\
\text { culture }\end{array}$ & $\begin{array}{c}\text { Culture } \\
\text { of } \\
\text { biopsied } \\
\text { specimen }\end{array}$ & $\begin{array}{c}\text { Direct } \\
\text { PCR of } \\
\text { biopsied } \\
\text { specimen }\end{array}$ & Treatment & Outcome & Reference \\
\hline 1 & $75 \mathrm{M}$ & $\begin{array}{l}\text { Hypertention } \\
\text { Coronary } \\
\text { artery disease }\end{array}$ & L5-S1 & Positive & NA & NA & $\begin{array}{l}\text { Meropenem 1w } \\
\text { Ertapenem 5w }\end{array}$ & Cure & (4) \\
\hline 2 & $64 \mathrm{M}$ & None & L5 & Positive & Negative & NA & $\begin{array}{l}\text { (Cefazolin+ } \\
\text { Fosfomycin) } 8 \mathrm{w}\end{array}$ & Cure & (5) \\
\hline 3 & $56 \mathrm{M}$ & $\begin{array}{l}\text { Bronchial } \\
\text { asthma }\end{array}$ & C6-7 & Positive & NA & NA & Ceftriaxone $6 \mathrm{w}$ & Cure & (6) \\
\hline 4 & $66 \mathrm{M}$ & $\begin{array}{l}\text { Diabetes, } \\
\text { Liver cirrhosis }\end{array}$ & L1-2 & Positive & Positive & Positive & $\begin{array}{l}\text { Ampicillin 1w } \\
\text { Oral Doxycycline 11w }\end{array}$ & Cure & (7) \\
\hline 5 & $55 \mathrm{M}$ & Hypertention & L4-5 & Negative & Negative & Positive & Ceftriaxone $8 w$ & Cure & (8) \\
\hline $\begin{array}{l}\text { Present } \\
\text { case }\end{array}$ & $65 \mathrm{M}$ & Epilepsy & Th11-L2 & Negative & Negative & Positive & $\begin{array}{l}\text { Ceftriaxone 6w } \\
\text { Oral Minocycline 24w }\end{array}$ & Cure & Our case \\
\hline
\end{tabular}

M: male, L: lumbar vertebra, C: cervical vertebra, Th: thoracic vertebra, NA: not applicable, w: week(s)

vertebral bodies and disks (Figure).

Two sets of blood culture were performed; however, no organism grew on culture. A percutaneous biopsy of the lumbar disk was performed. Bacteria were not observed on Gram staining. In addition, no growth was found on blood agar or chocolate II agar after $72 \mathrm{~h}$ of incubation at $35^{\circ} \mathrm{C}$ under $5 \% \mathrm{CO}_{2}$, nor in thioglycollate broth after 14 days at $35^{\circ} \mathrm{C}$.

Direct broad-range PCR with sequencing of the biopsied specimen was performed. The consensus sequence had the highest similarity $(1,433 / 1,441$ bp $99.41 \%$ match in GenBank, Accession No. NR_025941, 1,431/1,438 bp 99.51\% match in EzTaxon, Accession No. ABQT01000054) to the 16S rRNA gene of $H$. cinaedi.

We started the patient on ceftriaxone, and his low back pain and elevated CRP level gradually improved. We switched ceftriaxone to oral minocycline after six weeks, and he was discharged. Treatment with minocycline was continued for approximately six months, and there have been no signs of relapse during three months of follow-up.

\section{Discussion}

The course of the present case emphasizes two important clinical points. First, $H$. cinaedi should be suspected as a pathogen in vertebral osteomyelitis, even when conventional cultures are negative. Second, broad-range PCR with sequencing of biopsy specimens is particularly useful when conventional cultures cannot identify the causative organism of vertebral osteomyelitis.

$H$. cinaedi should be suspected as a pathogen in vertebral osteomyelitis even when conventional cultures are negative. Six cases of vertebral osteomyelitis with $H$. cinaedi have been reported, and two of these cultures were negative, including our case (Table) (4-8). H. cinaedi was detected on blood culture in four cases. A biopsy was performed in four 
cases, and the biopsy specimen culture was positive in only one case. In two cases, including our present case, broadrange PCR with sequencing directly performed using the biopsy specimen confirmed the presence of $H$. cinaedi, although the culture was negative. Several reasons for the inability to detect the causative organism have been suggested. First, prior antimicrobial exposure decreases the sensitivity of the conventional culture. However, in our case, no antibiotic had been used prior to performing culture. Second, fastidious organisms, including $H$. cinaedi, are difficult to culture. The detection of $H$. cinaedi is known to be particularly difficult because it rarely grows on traditional culture media (9). Nonselective media incubated in a microaerobic condition $\left(5 \% \mathrm{O}_{2}\right)$, ideally with hydrogen gas $(5-10 \%)$, or selective media such as Skirrow or Butzler Blaser were reported to be suitable for the isolation of $H$. cinaedi $(9,10)$. In our case, we used neither a microaerobic condition nor selective media because we did not suspect $H$. cinaedi to be the causative organism. In addition, $H$. cinaedi grows slowly under microaerobic conditions; therefore, a long incubation period is recommended for its detection. Four to ten days are considered necessary for a positive result with a culture bottle of an automatic blood culture system (10). Given the findings of this previous report, we prolonged the incubation time of blood culture to 10 days; however, we did not observe any organism growth.

The optimum antibiotic selection and duration for vertebral osteomyelitis with $H$. cinaedi have yet to be determined. Indeed, the selection of antimicrobials has varied in previous case reports (Table). We selected ceftriaxone and oral minocycline based on a previous report of successful treatment with these drugs for $H$. cinaedi bacteremia (11). A treatment duration of more than six weeks in all cases achieved favorable outcomes.

The present case suggests that broad-range PCR with sequencing of biopsy specimens is particularly useful when the causative organism of vertebral osteomyelitis cannot be identified using conventional cultures. Choi et al. reported that broad-range PCR with sequencing is more sensitive than routine culture for the etiological diagnosis of vertebral osteomyelitis (12). In their study, broad-range PCR with sequencing confirmed the causative organism in 16 cases of vertebral osteomyelitis in which biopsy specimen culture had been negative. Given that three-quarters of the patients had been treated with antimicrobial agents, the authors concluded that broad-range PCR would be particularly useful for patients with a history of antimicrobial therapy. The findings of our case further imply that this method might be useful when the pathogen is a fastidious organism, such as

\section{H. cinaedi.}

In conclusion, we encountered a rare case of vertebral osteomyelitis caused by $H$. cinaedi identified using broadrange PCR with sequencing of a biopsy specimen that had not been detected with conventional culture. The findings of our case suggest that performing broad-range PCR with sequencing should be considered for the detection of the causative organism when blood or biopsy specimen culture fails.

The authors state that they have no Conflict of Interest (COI).

\section{References}

1. Zimmerli W. Clinical practice. Vertebral osteomyelitis. N Engl J Med 362: 1022-1029, 2010.

2. Rampini SK, Bloemberg GV, Keller PM, et al. Broad-range $16 \mathrm{~S}$ rRNA gene polymerase chain reaction for diagnosis of culturenegative bacterial infections. Clin Infect Dis 53: 1245-1251, 2011.

3. Petti CA. Detection and identification of microorganisms by gene amplification and sequencing. Clin Infect Dis 44: 1108-1114, 2007.

4. Smith G, Amber N, Wolk DM, Hoover SE. Helicobacter vertebral osteomyelitis in an immunocompetent adult. Infect Dis Clin Pract 20: 61-62, 2013.

5. Haruki $\mathrm{Y}$, Hagiya $\mathrm{H}$, Hashimoto $\mathrm{T}$, et al. Pyogenic spondylitis and diskitis caused by Helicobacter cinaedi in an immunocompetent adult patient. Intern Med 54: 2415-2418, 2015.

6. Murata S, Suzuki H, Sakamoto S, et al. Helicobacter cinaediassociated vertebral osteomyelitis in an immunocompetent patient. Intern Med 54: 3221-3224, 2015.

7. Yoshizaki A, Takegawa H, Doi A, Mizuno Y, Nishioka H. Vertebral osteomyelitis caused by Helicobacter cinaedi. J Clin Microbiol 53: 3054-3056, 2015.

8. Sekikawa Y, Hongo I, Oda R, Ohkusu K. Helicobacer cinaedi vertebral osteomyelitis identified by $16 \mathrm{~S}$ rDNA analysis of tissue in an immunocompetent adult [abstract]. Open Forum Infect Dis 2: 1516, 2015.

9. Matsumoto T, Goto M, Murakami H, et al. Multicenter study to evaluate bloodstream infection by Helicobacter cinaedi in Japan. J Clin Microbiol 45: 2853-2857, 2007.

10. Kawamura Y, Tomida J, Morita Y, Fujii S, Okamoto T, Akaike T. Clinical and bacteriological characteristics of Helicobacter cinaedi infection. J Infect Chemother 20: 517-526, 2014.

11. Uwamino Y, Muranaka K, Hase R, Otsuka Y, Hosokawa N. Clinical features of community-acquired Helicobacter cinaedi bacteremia. Helicobacter 21: 24-28, 2016.

12. Choi SH, Sung H, Kim SH, et al. Usefulness of a direct $16 \mathrm{~S}$ rRNA gene PCR assay of percutaneous biopsies or aspirates for etiological diagnosis of vertebral osteomyelitis. Diagn Microbiol Infect Dis 78: 75-78, 2014.

The Internal Medicine is an Open Access article distributed under the Creative Commons Attribution-NonCommercial-NoDerivatives 4.0 International License. To view the details of this license, please visit (https://creativecommons.org/licenses/ by-nc-nd/4.0/).

(C) 2018 The Japanese Society of Internal Medicine Intern Med 57: 1475-1477, 2018 